03.4

\title{
Исследование процесса коалесценции капель эмульсии в неоднородном переменном электрическом поле при наличии межфазной асфальтеновой пленки на границе раздела масло-вода
}

\author{
(C) А.И. Муллаянов, Р.Ш. Осипова, А.А. Мусин, Л.А. Ковалева
}

Центр микро- и наномасштабной динамики дисперсных систем Башкирского государственного университета, Уфа, Россия

E-mail: mullayanovalmir@mail.ru

Поступило в Редакцию 15 марта 2021 г.

В окончательной редакции 15 марта 2021 г.

Принято к публикации 2 октября 2021 г.

\begin{abstract}
Изучено поведение эмульсии типа „вода в масле“, стабилизированной асфальтенами, под действием неоднородного переменного электрического поля. Методика эксперимента основана на использовании методов микрофлюидики, оптической микроскопии и высокоскоростной видеосъемки. Получены количественные оценки параметров, характеризующих динамику разрушения эмульсии, в зависимости от частоты и амплитуды приложенного поля. Метод будет полезен при разработке эффективных способов разрушения эмульсий и модификации существующих технологий разделения нефтяных эмульсий на фазы.
\end{abstract}

Ключевые слова: асфальтены, эмульсия, электрическое поле, коалесценция, оптическая микроскопия, высокоскоростная видеосъемка, микрожидкостное устройство.

DOI: 10.21883/PJTF.2022.02.51917.18768

Изучение эмульсий под действием электрического поля является областью активных исследований [1]. Большинство из них направлено на решение задач разделения нефтяных эмульсий на отдельные фазы. Проблема разделения нефтяных эмульсий заключается в наличии на межфазной поверхности асфальтенов, смол, парафинов, которые увеличивают стабильность эмульсии. Важным и перспективным методом разделения нефтяных эмульсий является электрическое воздействие [2,3]. В настоящее время широкое применение получили экспериментальные методы микрофлюидики, в которых электрическое поле используется для управления микрообъектами дисперсных систем [4]. Преимуществом использования методов микрофлюидики является возможность детального изучения процессов, происходящих в дисперсных системах на микромасштабном уровне. В настоящей работе использована система микроэлектродов, с помощью которых создается электрическое поле в исследуемой ячейке, по аналогии с технологическими решениями, применяемыми в микрофлюидике. Основной целью работы является изучение динамики разрушения модельной асфальтеновой эмульсии при воздействии неоднородного переменного электрического поля. В качестве объекта исследования использована эмульсия типа „вода в масле“, состоящая из микрокапель воды размером 1-100 $\mu \mathrm{m}$, взвешенных в тетрадекане и покрытых асфальтеновой оболочкой. Наличие асфальтеновой оболочки вокруг капель воды установлено с помощью атомно-силовой микроскопии. Методика представлена в работе [5] и заключается в исследовании капель с оболочкой на поверхности стекла после испарения жидкости внутри капли.
Для изучения воздействия электрического поля на эмульсию спроектирована и собрана экспериментальная установка, схема которой представлена на рис. 1. Важным элементом установки является экспериментальная ячейка 5, которая изготовлена из двух прозрачных стеклянных подложек, между которыми вставлена тефлоновая прокладка толщиной $100 \mu \mathrm{m}$. В тефлоновой прокладке вырезан прямоугольный канал, в который закачивается исследуемая жидкость через входной порт на верхней подложке. Конфигурация электродов представлена на вставке к рис. 1.

В качестве нижней подложки использовано стекло с электропроводящим слоем ITO (оксид индия-олова, indium tin oxide), на поверхности которого методом фотолитографии вытравлены электроды пилообразной формы с расстоянием $200 \mu \mathrm{m}$ между вершинами. Экс-

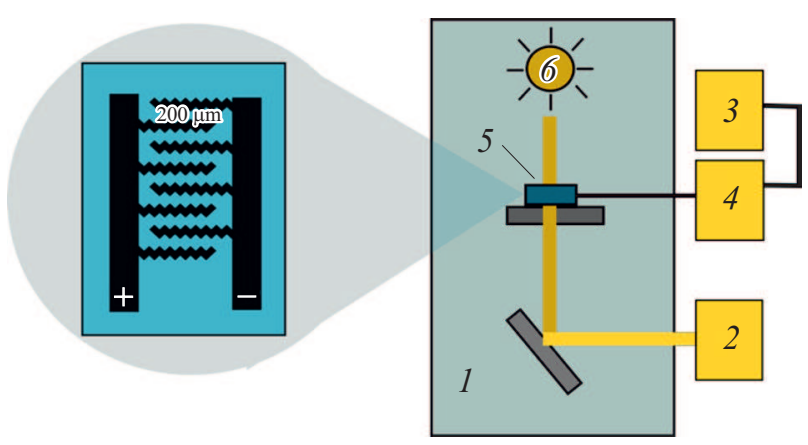

Рис. 1. Схема экспериментальной установки на базе микроскопа. 1 - зеркало, 2 - высокоскоростная камера, 3 генератор сигналов, 4 - усилитель, 5 - экспериментальная ячейка, 6 - источник света. 


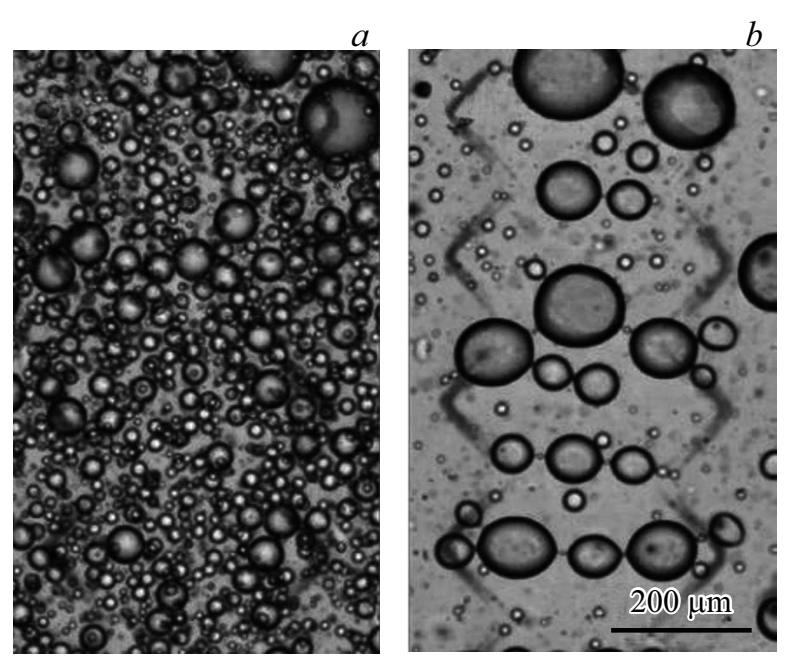

Рис. 2. Характерные картины распределения капель эмульсии до $(a)$ и после $(b)$ воздействия электрического поля в диапазоне частот $0.05-15 \mathrm{kHz}$ при напряжении $75-300 \mathrm{~V}$ на микроструктуру эмульсии. периментальная ячейка размещалась на предметном столике оптического микроскопа IX71 (Olympus). На систему электродов подавалось переменное двуполярное напряжение от генератора сигналов произвольной формы 33522A (Agilent Technologies), усиленное с помощью усилителя Tabor 9100 (Tabor Electronics, Ltd.). Амплитуда (пик-пик) приложенного напряжения варьировалась в диапазоне $75-300 \mathrm{~V}$, а частота изменялась в диапазоне $0.05-15 \mathrm{kHz}$. Высокоскоростная съемка эксперимента производилась при помощи камеры FASTCAM SA5 (Photron) при частоте 250 кадров в секунду. Из видеоряда процесса воздействия на эмульсию были получены изображения микроструктуры эмульсии до и после воздействия электрическим полем (рис. 2). Время воздействия для всех экспериментов было равно $5 \mathrm{~s}$. При этом в ходе исследований было установлено, что основные изменения микроструктуры изучаемой эмульсии происходят за доли секунды независимо от частоты и напряжения приложенного поля. Из рис. 2, $a$ видно,
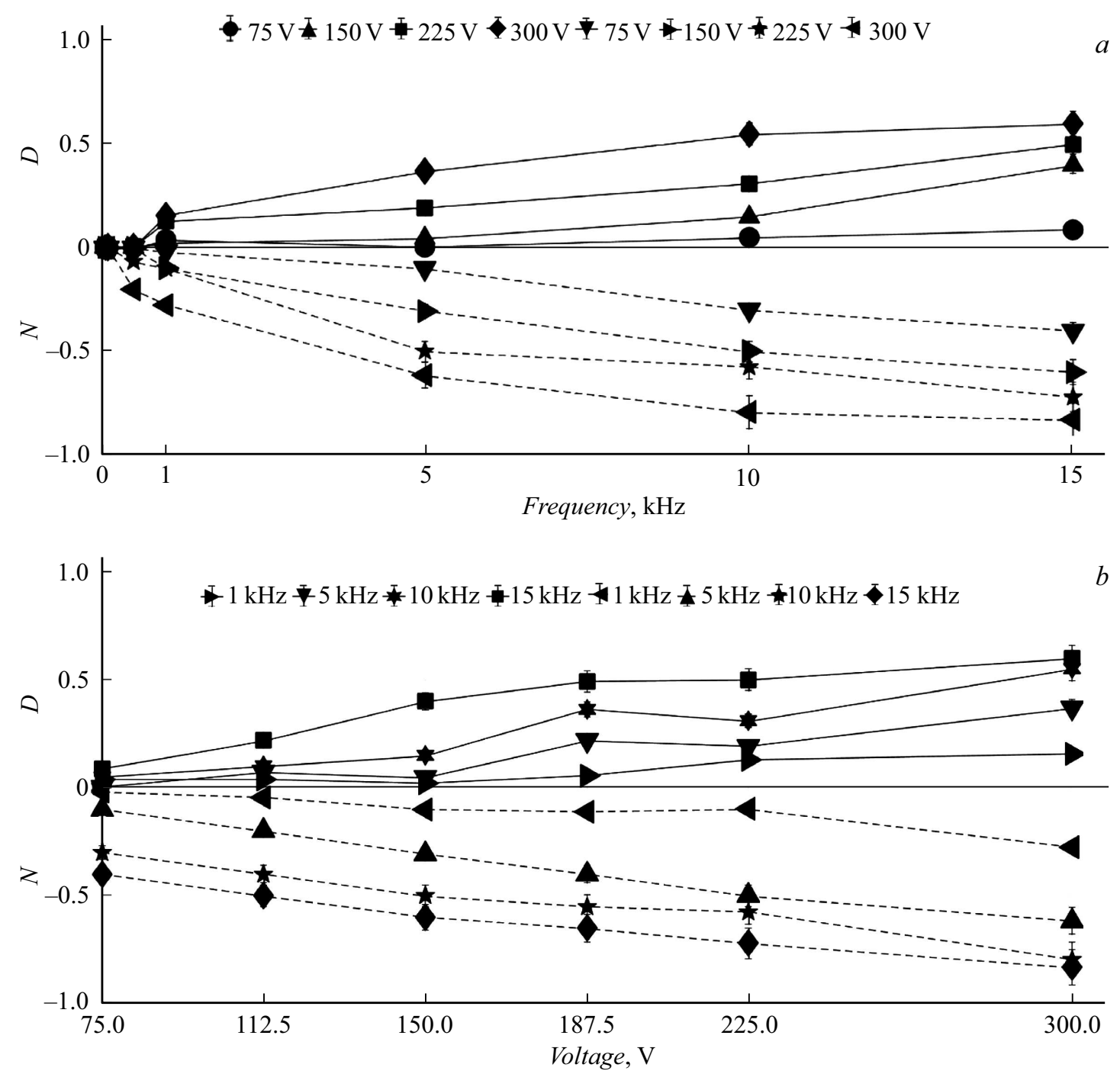

Рис. 3. Зависимости относительного изменения количества капель $(N)$ и относительного изменения среднего диаметра капель $(D)$ от частоты $(a)$ и напряжения $(b)$ электрического поля. 
что до воздействия капли эмульсии были равномерно распределены в наблюдаемой области ячейки. В ходе экспериментальных исследований в диапазонах частот $0.05-15 \mathrm{kHz}$ и напряжений 75-300 V обнаружено, что при включении электрического поля капли начинают двигаться в области межэлектродного пространства, где сталкиваются и соединяются (коалесцируют), что приводит к образованию капель большего размера (рис. 2, b).

Все изображения обработаны с помощью программы ImageJ с целью подсчета количества капель и их диаметров. Для определения эффективности воздействия были введены параметр $N=\left(N_{2}-N_{1}\right) / N_{1}$, характеризующий изменение количества капель после $5 \mathrm{~s}\left(N_{2}\right)$ относительно начального состояния $\left(N_{1}\right)$, и параметр $D=\left(D_{2}-D_{1}\right) / D_{1}$, характеризующий относительное изменение среднего диаметра капель после $5 \mathrm{~s}\left(D_{2}\right)$ относительно начального состояния $\left(D_{1}\right)$. Зависимости этих параметров от частоты и напряжения приложенного электрического поля приведены на рис. 3 .

Из рис. 3, $a$ видно, что при частоте поля до $1 \mathrm{kHz}$ и максимальном напряжении $300 \mathrm{~V}$ происходит скачкообразное изменение относительного диаметра капель $D$ до $18 \%$ и их количества $N$ до $30 \%$. Увеличение частоты до $5 \mathrm{kHz}$ приводит к изменению относительного количества капель $N$ до $60 \%$ и диаметра $D$ до $38 \%$. При дальнейшем увеличении частоты до 10 и $15 \mathrm{kHz}$ происходит рост интенсивности относительного изменения количества и диаметра капель: $N=80 \%, D=58 \%$ и $N=82 \%, D=60 \%$ соответственно. Таким образом, можно утверждать, что максимальные изменения параметров $N$ (уменьшение относительного числа капель) и $D$ (увеличение относительного среднего размера капель) происходят при частотах $5-10 \mathrm{kHz}$ при напряжении сигнала $187.5-300 \mathrm{~V}$.

Результаты настоящей работы с асфальтеновыми эмульсиями имеют ряд отличий от полученных ранее в работе [6], в которой были исследованы капли эмульсии, стабилизированные поверхностно-активным веществом Span 80, и было показано, что в диапазонах напряжений электрического поля 75-300 V и частот $0.1-1 \mathrm{kHz}$ происходит интенсивное разделение эмульсии. Сравнивая результаты этих двух работ, можно отметить, что для коалесценции капель, стабилизированных асфальтенами, требуются на порядок бо́льшие частоты электрического поля.

Таким образом, результаты проведенных экспериментальных исследований показали, что с увеличением напряжения приложенного электрического поля эффект коалесценции усиливается. При этом в отличие от эмульсий, стабилизированных поверхностно-активными веществами типа Span 80, воздействие неоднородного переменного электрического поля на эмульсии, стабилизированные выделенными из нефти асфальтенами, носит ступенчато нелинейный характер. В рассмотренном случае наиболее интенсивное воздействие происходит в диапазоне частот $1-10 \mathrm{kHz}$. При этом продолжительность изменения микроструктуры эмульсии не превышает $1 \mathrm{~s}$.

\section{Финансирование работы}

Работа поддержана Российским научным фондом (грант № 19-11-00298).

\section{Конфликт интересов}

Авторы заявляют, что у них нет конфликта интересов.

\section{Список литературы}

[1] M.M. Abdulredha, H.S. Aslina, C.A. Luqman, Arab. J. Chem., 13 (1), 3403 (2020). DOI: 10.1016/j.arabjc.2018.11.014

[2] S.A. Raya, I.M. Saaid, A.A. Ahmed, A.A. Umar, J. Petrol. Explor. Prod. Technol., 10 (4), 1711 (2020). DOI: $10.1007 / \mathrm{s} 13202-020-00830-7$

[3] L. Kovaleva, R. Zinnatullin, A. Musin, A. Gabdrafikov, R. Sultanguzhin, V. Kireev, Coll. Surf. A, 614, 126081 (2021). DOI: $10.1016 /$ j.colsurfa.2020.126081

[4] H. Zhang, H. Chang, P. Neuzil, Micromachines, 10 (6), 423 (2019). DOI: $10.3390 / \mathrm{mi} 10060423$.

[5] Ю.С. Замула, А.И. Муллаянов, Э.С. Батыршин, Л.А. Ковалева, Вестн. Башкир. ун-та, 25 (2), 245 (2020). DOI: $10.33184 /$ bulletin-bsu-2020.2.3

[6] Э.С. Батыршин, А.И. Муллаянов, С.П. Саметов, Письма в ЖТФ, $46 \quad$ (5), 52 (2020). DOI: $10.21883 /$ PJTF.2020.05.49111.18149 [E.S. Batyrshin, A.I. Mullayanov, S.P. Sametov, Tech. Phys. Lett., 46 (3), 253 (2020). DOI: 10.1134/S1063785020030049]. 